\title{
Food taboos of malay pregnant women attending antenatal check-up at the maternal health clinic in Kuala Lumpur
}

\author{
Maznorila Mohamad* and Chong Yee Ling \\ Division of Nutrition and Dietetics, School of Health Sciences, International Medical University, Malaysia
}

\begin{abstract}
Food taboos are generally practiced during pregnancy in many cultures. Certain food or activities are not allowed during pregnancy in order to safeguard the unborn child and prevent any negative outcomes to the mother and the baby alike. Passed on from one generation to another, most of these taboos are based on learned behaviour, either acquired mostly by instruction from parents and family members or observation from close relatives and friends. The main aim of the study was to determine the prevalence and types of food taboos and its reason for avoidance. The secondary objective was to determine its association with rates of weekly weight gain of the pregnant women. A cross sectional study was conducted among 104 Malay pregnant women ranging from age 20 to 46 years. Information on socio-demographic profile and practices pertaining to food taboo was collected using a structured questionnaire. Weight gain status during pregnancy was assessed by comparing the current weight with pre-pregnancy weight. About $70.2 \%$ of the respondents avoided at least one food item due to food taboos. Pineapple and sugar cane drink were regarded as taboo foods by more than half of the subjects $(70.2 \%$ and $59.6 \%$ respectively), followed by hot foods (47.1\%), carbonated drinks (39.4\%) and cold foods (12.5\%). The most common reason for avoiding foods were fear of abortion (95.2\%), followed by fear of excessive bleeding during labor (34.6\%), baby born with deformities (27.9\%) and other reasons such as difficult labor, unnecessary sickness, induced vomiting and edema (19.2\%). Multiparous women with 3 pregnancies or more were found to be associated with the practice of food taboos ( $\leq \leq 0.05)$. About $71.2 \%$ of women who practiced food taboos had an inadequate weight gain and there was a significant association between prevalence of food taboos with weekly rates of weight gain of the pregnant women ( $<0.05$ ). Prevalence of food taboos was high among the Malay pregnant women and the main reason for adhering to food taboos was fear of abortion. A significant association was found between the prevalence of food taboo with weekly rates of weight gain. Nutrition education should be conducted in all health centers to help pregnant women with a healthier food choice to ensure a healthy pregnancy.
\end{abstract}

\section{Introduction}

Food taboos probably exist in one form or another in every society. Dietary rules and regulations may govern particular phase of human life cycle and maybe associated with special events such as a menstrual period, pregnancy, childbirth, lactation, wedding, funeral, etc. Meter-Rochow defined food taboo (or prohibition) as a deliberate avoidance of a food item for reasons other than simple dislike from food preferences [1].

Food taboos are commonly practiced during pregnancy in many cultures [2-6]. Certain food or activities are not allowed during pregnancy in order to safeguard the unborn child and prevent any negative outcomes to the mother. Passed on from one generation to another, most of these taboos are based on learned behaviour, either acquired mostly by instruction from parents and family members or observation from close relatives and friends who practices it.

Many of these cultural patterns have to do with avoiding other problematic events or situations [2]; hence changing the food habit during pregnancy are observed by the women in order to make delivery easy or to prevent the child from being marred or deformed. For example; in the Philippines, women are told to eat raw egg just before delivery to help lubricate the birth canal and Chinese women avoid eating crabs due to the belief that this might make their baby mischievous or babies may be born with 11 fingers [7].

In many cultures, strong taboos limit the amounts, or kinds, of food a pregnant woman may choose; for example protein foods are often denied to pregnant women in various part of Africa and many other populations [8]. A study in Brazil found that women should not eat game meat and fish at the same time during pregnancy due to the belief that such combinations can kill or cause harm such as congestion or vomiting [9]; whilst women in Tanzania abstain from eating meat, fearing that the baby they deliver might take on the characteristics of the animal they consumed. Many studies have reported that pregnant women in various parts of the world are forced to abstain from nutritious foods as part of their traditional food belief [5]. Women in the southern part of India commonly avoid raw papaya during pregnancy because they believe that papaya can cause abortion $[10,11]$ and Mexican women belief that eggs can make the baby smell bad [7].

Altering roles and activities during pregnancy or following childbirth are well known among anthropologists [12]. The reasons for these changes are numerous and diverse. There is a common belief that women and infants were more vulnerable during post-partum period [13]. Women in many societies observed a series of postpartum practices which aimed to protect the mothers and their newborns [14]. In Malaysia, similar taboos also exist. Traditional postpartum care in

Correspondence to: Maznorila Mohamad, Division of Nutrition and Dietetics, School of Health Sciences, International Medical University, No 126 Jalan Jalil Perkasa, Bukit Jalil 57000, Kualalampur, Malaysia; E-mail: Maznorila_mohamad@imu.edu.my

Key words: Malay, pregnant women, food taboos, weight gain status

Received: December 31, 2015; Accepted: January 13, 2016; Published: January 16,2016 
Malaysia is widely practiced regardless of the socio-demographic and cultural differences. The women in Malaysian societies observe 30 to 44 days of confinement period in which adherence to the food restrictions is the one of the most common practice [15].

While there were quite a number of studies have been done relating on food taboos after childbirth or during confinement in Malaysia $[12,14,16,17]$; however a literature search of available resources found very few studies solely focused on food taboos during pregnancy $[6,18]$ Most of the available studies presented the practices among the indigenous women in Peninsular Malaysia and not the Malays. Though very few reports found on food taboos among Malay women during pregnancy $[19,20]$, this does not mean that the practice rarely exists or the Malay women do not have a distinctive food taboos while pregnant. Unlike many other cultures, perhaps the Malay does not regard pregnancy as a condition that requires special precautions as compare to the period of post-partum [12]. This observation appears to support a study by Millis which shows that the food intake of Malay women was unchanged during pregnancy, but noted that they avoided certain food only during confinement [21].

Pregnancy is the most nutritionally demanding stage in a woman's life. This stage demands extra calories and essential nutrients are needed every day to support the growth of the fetus [22]. Severe food avoidance during pregnancy might deplete the body of important nutrients which can adversely affect pregnancy and birth outcomes. Evidence showed that the amount of weight gained during pregnancy can affect the immediate and future health of a woman and her baby [23,24]. Therefore, attention to appropriate dietary behaviour and proper nutrient intake is of utmost importance for adequate nourishment to both, the mother and the fetus. Lack of accurate information concerning food intake of pregnant women could be a hindrance for the improvement of their nutritional status. Thus, the purpose of this study is to determine the prevalence of food taboos among Malay pregnant women, types of food taboos and its reason for avoidance. This paper will assess the association of food taboo practices and its effect on weight gain during pregnancy of Malay women attending antenatal check-up at the maternal and child health clinic in Kuala Lumpur.

\section{Materials and methods}

\section{Ethical clearance}

This study was approved by the International Medical University Joint Committee of the Research and Ethics Committee bearing the grant no. N\&D 1-01/2008(17)2010. The purpose of the study was informed to the subjects prior to their consent for the data collection.

\section{Subjects}

A total of 104 Malay pregnant women from all trimesters were recruited for this study from a maternal and child health clinic. The subjects were those who attended a routine antenatal check-up at the clinic. Pregnant women included in this study were free from any obstetrical and medical complications known to affect fetal growth, such as hyperemesis gravidarum, gestational diabetes mellitus (GDM) and hypertension. Pregnant women who had food intolerance and food allergies resulting in avoidance of certain foods due to adverse reaction were excluded.

\section{Data collection}

Questionnaire and interview: A face to face interview was conducted for each subject using a set of structured questionnaires which had been pre-tested in a pilot study. The questionnaires were developed to elicit information on the socioeconomic and demographic background of the subjects and also the practices of food taboos observed during pregnancy. In order to gather information on the food taboos, the subjects were asked to list down the food they avoided and state the reason why certain foods were considered as taboos. Some of the questions were open-ended questions purposely design to enable the interviewer to probe in greater detail about a particular matter while allowing the subjects the opportunity to answer freely.

Obstetric history and gestational age: Data on subject's obstetric history was collected from the medical records with permission from the subjects and the sanctions of the clinic. The gestational age was calculated from the subject's last menstrual period.

Anthropometric assessment: The pre-pregnancy nutritional status of the subjects was evaluated using Body Mass Index (BMI). The nutritional status was defined as underweight, normal, overweight or obese, according to WHO BMI standards [25]. The subjects' prepregnancy weight was obtained from the medical records or from their recalled (if there was no record found on subject's pre-pregnancy weight). Subjects' height was measured to the nearest $0.1 \mathrm{~cm}$ using Microtoise, which was suspended 2 meters from the flat surface floor against a smooth and flat wall. Subjects were required to stand straight without shoes.

The subjects' current body weight was measured using Tanita digital weighing scale to the nearest $0.1 \mathrm{~kg}$ in their lightest clothing with shoes removed. From the measured current body weight, rate of weight gain per week by the subjects can be calculated by subtracting their pre-pregnancy weight from the current weight and then divided by week of gestation.

Pre-pregnancy BMI and the rate of weight increase per week will then compare to the Institute of Medicine (IOM) 2009 [26] guide for the recommended weight gain during gestation. The subjects then are classified as having inadequate, adequate or excessive weight gain rate.

\section{Statistical analysis}

Data analyses were analyzed using SPSS (Statistical Package for the Social Sciences) Version 20.0.

\section{Results}

\section{Socio-demographic background}

Table 1 shows the socio-demographic characteristics of the pregnant women at the time of the interview. More than half (53.8\%) of the subjects were young women aged between 20-29 years old, followed by $41.3 \%$ between $30-39$ years old and $4.8 \%$ were at or above 40 years old. The mean age of the subjects was $30.0 \pm 4.8$ years, ranging from 20 to 46 years.

The majority of subjects have completed secondary education (83.6\%) whereas $16.4 \%$ have received tertiary education. Regarding estimated monthly household income, about one third (30.8\%) reported the household income of below RM2,000 per month. Of the remaining, half $(50.0 \%)$ of the subjects had a household income of between RM2,100-4,000, another $15.4 \%$ had household income between RM4,001-6,000 while only $3.8 \%$ had household income above RM6,000.

At the time of data collection, $26.9 \%$ of the subjects were at gravida 
Table 1. Socio-demographic characteristics of the pregnant women $(\mathrm{n}=104)$.

\begin{tabular}{|c|c|c|c|}
\hline Characteristic & & $\mathbf{n}$ & Percentage (\%) \\
\hline \multirow[t]{3}{*}{ Age (years) } & $20-29$ & 56 & 53.8 \\
\hline & $30-39$ & 43 & 41.3 \\
\hline & $\geq 40$ & 5 & 4.8 \\
\hline \multirow[t]{3}{*}{ Education level } & Lower secondary & 62 & 59.6 \\
\hline & Upper secondary & 25 & 24.0 \\
\hline & Tertiary & 17 & 16.4 \\
\hline \multirow[t]{7}{*}{ Household income per month (RM) } & 1,000 and below & 0 & 0.0 \\
\hline & $1,001-2,000$ & 32 & 30.8 \\
\hline & $2,001-3,000$ & 24 & 23.1 \\
\hline & $3,001-4,000$ & 28 & 26.9 \\
\hline & $4,001-5,000$ & 11 & 10.6 \\
\hline & $5,001-6,000$ & 5 & 4.8 \\
\hline & $>6,000$ & 4 & 3.8 \\
\hline \multirow[t]{7}{*}{ Gravidity } & Gravida 1 & 28 & 26.9 \\
\hline & Gravida 2 & 37 & 35.6 \\
\hline & Gravida 3 & 20 & 19.2 \\
\hline & Gravida 4 & 13 & 12.5 \\
\hline & Gravida 5 & 5 & 4.8 \\
\hline & Gravida 6 & 0 & 0.0 \\
\hline & Gravida 7 & 1 & 1.0 \\
\hline
\end{tabular}

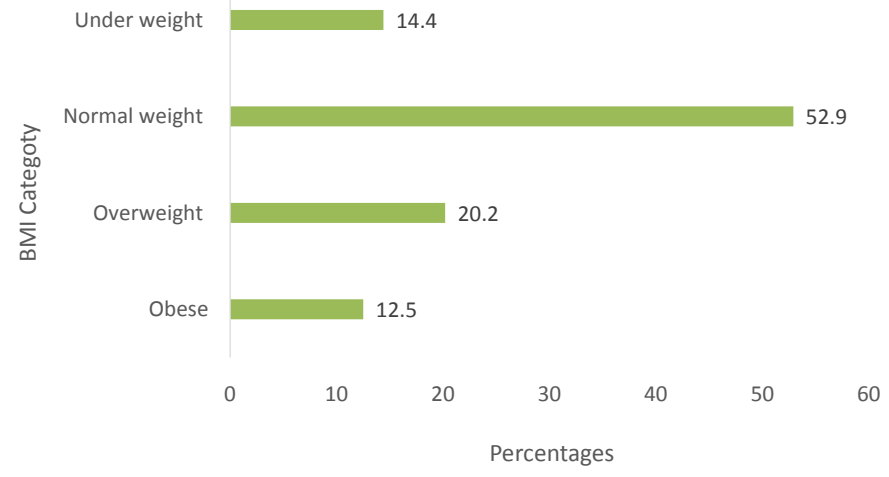

Figure 1. Pre-pregnancy BMI of the subjects.

1 , more than one third (35.6\%) were at gravida 2 , and $37.5 \%$ of them have at least had experienced more than 2 pregnancies.

\section{Pre-pregnancy BMI status}

Figure 1 shows that $14.4 \%$ of the women suffered from chronic energy deficiency, but more than half (52.9\%) of them were at their normal weight before pregnancy. However, one fifth $(20.2 \%)$ of them were overweight and a smaller percentage $(12.5 \%)$ were obese.

\section{Weight gain status of the subjects}

The weight gain status of the subjects is categorized based on IOM 2009 classification and presented in Table 2. About $64.4 \%$ of the subjects had inadequate rates of weekly weight gain and $15.4 \%$, had an excessive rate of weekly weight gain.

\section{Prevalence of food taboos and its source of information}

The prevalence rate of pregnant women adhering to specific food taboos during their pregnancy was $70.2 \%$, of which, $18.3 \%$ avoided eating at least one food item. The majority of subjects (63.5\%) acquired information about food taboos from their family members, either from grandmothers, mothers or older siblings. Health professionals such as physicians, nutritionists and nurses were the next most credible source that the pregnant women relied on $(27.9 \%)$, followed by social media (6.7\%) and friends (1.9\%).

However, nearly one third (29.8\%) of subjects reported that they did not abstain from eating any food because they believed good pregnancy outcomes is the result from eating healthily.

\section{Type of food taboos and its reason for avoidance}

Type of food avoided and the different reasons for this avoidance are presented in Table 3. The most commonly taboo foods were pineapple (70.2\%), followed by sugarcane juice (59.6\%), 'hot foods' (47.1\%), carbonated drinks (39.4\%), 'tapai' or fermented glutinous rice (33.7\%), bamboo shoots (18.3\%), 'cold foods' (12.5\%) and others (35.6\%).

The main reason for food avoidance was mainly due to the belief that consuming these foods will lead to abortion (95.2\%), followed by excessive bleeding during labor (34.6\%) and the baby born with deformities (27.9\%). Other reasons stated by the women were to avoid unnecessary sickness, edema, vomiting and/or dizziness. They also fear of facing difficult labor, having babies with dark skin and/or with cognitive impairment.

\section{Association between socio-demographic characteristics and food taboo practices}

There is a significant association $(\mathrm{p}<0.05)$ between food taboo practices with the number of pregnancies of the study subjects (Table 4). However subjects' age, education level, monthly household income and pre-pregnancy BMI do not show any association with food avoidance during pregnancy ( $\mathrm{p}>0.05)$.

\section{Association between food taboo practices and weight gain}

Table 5 shows a significant association between food taboos and the rate of weight gain among the pregnant women $(\mathrm{p}<0.05)$. About $71.2 \%$ of the pregnant mother had an inadequate weight gain, $8(11.0 \%)$ had an adequate weight gain and $13(17.8 \%)$ had excessive weight gain during pregnancy. Those who did not adhere to the food taboo practice apparently had a slightly lower percentage of inadequate weight gain (51.6\%) as compared to those who practiced food taboo (71.2\%).

\section{Discussion}

Majority of the subjects $(70.2 \%)$ in this study avoided at least one type of food while pregnant. This finding clearly shows that the practice

Table 2. Pre-pregnancy BMI and subjects' rates of weekly weight gain ( $\mathrm{n}=104)$.

\begin{tabular}{|c|c|c|c|c|c|}
\hline \multirow{2}{*}{$\begin{array}{l}\text { Pre- } \\
\text { pregnancy } \\
\text { BMI }\left(\mathrm{kg} / \mathrm{m}^{2}\right)\end{array}$} & \multirow{2}{*}{$\begin{array}{l}n \\
(\%)\end{array}$} & \multirow{2}{*}{$\begin{array}{c}\text { * Rates of weight } \\
\text { gain } 2^{\text {nd }} \text { and } 3^{\text {rd }} \\
\text { trimester } \\
\text { (mean range in } \mathrm{kg} / \\
\text { week) }\end{array}$} & \multicolumn{3}{|c|}{ Rates of weight gain } \\
\hline & & & $\begin{array}{c}\text { Inadequate } \\
\mathbf{n}=67 \\
(64.4 \%)\end{array}$ & $\begin{array}{c}\text { Adequate } \\
\mathbf{n}=21 \\
(20.2 \%)\end{array}$ & $\begin{array}{c}\text { Excessive } \\
n=16 \\
(15.4 \%)\end{array}$ \\
\hline $\begin{array}{l}\text { Underweight } \\
(<18.5)\end{array}$ & $15(14.4)$ & $0.45-0.59$ & $\begin{array}{c}12 \\
(11.5)\end{array}$ & $\begin{array}{c}2 \\
(1.9)\end{array}$ & $\begin{array}{c}1 \\
(1.0)\end{array}$ \\
\hline $\begin{array}{l}\text { Normal } \\
(18.5-24.9)\end{array}$ & $55(52.9)$ & $0.36-0.45$ & $\begin{array}{c}38 \\
(36.6)\end{array}$ & $\begin{array}{c}8 \\
(7.7)\end{array}$ & $\begin{array}{c}9 \\
(8.6)\end{array}$ \\
\hline $\begin{array}{l}\text { Overweight } \\
(25.0-29.9)\end{array}$ & $21(20.2)$ & $0.23-0.32$ & $\begin{array}{c}10 \\
(9.6)\end{array}$ & $\begin{array}{c}6 \\
(5.8)\end{array}$ & $\begin{array}{c}5 \\
(4.8)\end{array}$ \\
\hline $\begin{array}{l}\text { Obese } \\
(\geq 30)\end{array}$ & $13(12.5)$ & $0.18-0.27$ & $\begin{array}{c}7 \\
(6.7)\end{array}$ & $\begin{array}{c}5 \\
(4.8)\end{array}$ & $\begin{array}{c}1 \\
(1.0)\end{array}$ \\
\hline
\end{tabular}

*Rates for weight gain during pregnancy based on IOM 2009 recommendation which assumed $0.5-2.0 \mathrm{~kg}$ weight gain in the first trimester. 
Table 3. Type of foods avoided and reasons for practicing food taboos during pregnancy among Malay women ( $\mathrm{n}=104)$.

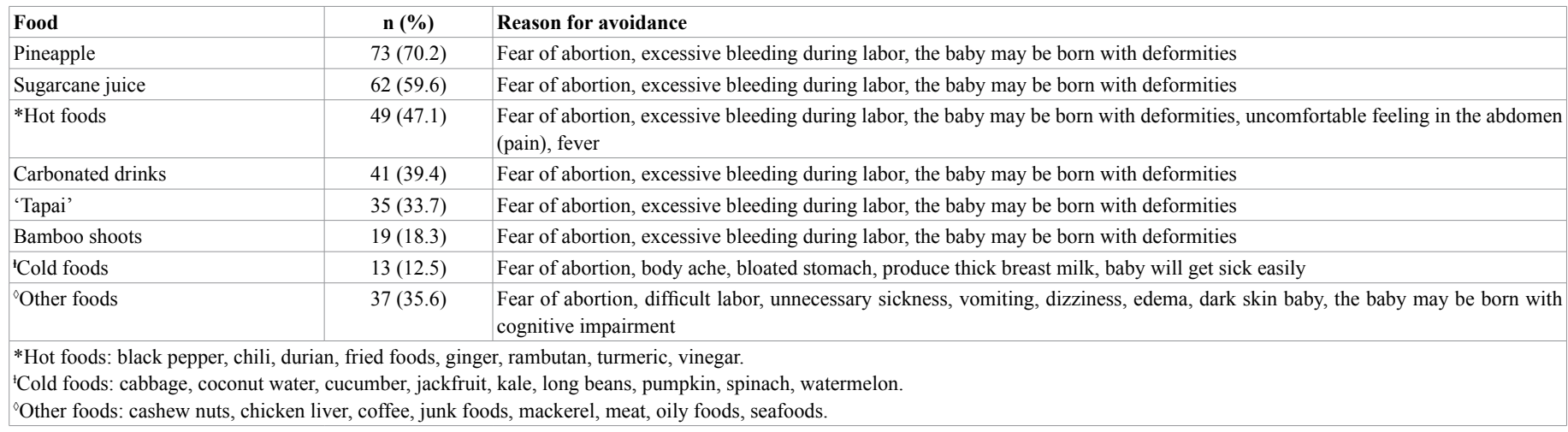

Table 4. Association of socio-demographic characteristics with food taboo practices.

\begin{tabular}{|c|c|c|c|c|c|}
\hline \multirow{2}{*}{\multicolumn{2}{|c|}{ Variables }} & \multicolumn{2}{|c|}{ Food avoidance/taboo } & \multirow[t]{2}{*}{$\chi^{2}(\mathrm{df})$} & \multirow[t]{2}{*}{ p value } \\
\hline & & Yes $(n=73)$ & No $(n=31)$ & & \\
\hline \multirow[t]{3}{*}{ Age (years) } & $20-29$ & 42 & 14 & \multirow{3}{*}{$1.974(2)$} & \multirow{3}{*}{0.373} \\
\hline & $30-39$ & 27 & 16 & & \\
\hline & $\geq 40$ & 4 & 1 & & \\
\hline \multirow[t]{3}{*}{ Education level } & Lower secondary & 42 & 20 & \multirow{3}{*}{$1.572(2)$} & \multirow{3}{*}{0.456} \\
\hline & Upper Secondary & 20 & 5 & & \\
\hline & Tertiary & 11 & 6 & & \\
\hline \multirow[t]{3}{*}{ Monthly household income (RM) } & $\leq 2000$ & 22 & 10 & \multirow{3}{*}{$5.791(2)$} & \multirow{3}{*}{0.055} \\
\hline & $2001-4000$ & 41 & 11 & & \\
\hline & $\geq 4001$ & 10 & 10 & & \\
\hline \multirow[t]{3}{*}{ Gravidity } & Gravida 1 & 23 & 5 & \multirow{3}{*}{$5.984(2)$} & \multirow{3}{*}{$0.050 *$} \\
\hline & Gravida 2 & 28 & 9 & & \\
\hline & $\geq$ Gravida 3 & 22 & 17 & & \\
\hline \multirow[t]{4}{*}{ BMI $\left(\mathrm{kg} / \mathrm{m}^{2}\right)$} & $<18.5$ & 13 & 2 & \multirow{4}{*}{2.568} & \multirow{4}{*}{0.463} \\
\hline & $18.5-24.9$ & 38 & 17 & & \\
\hline & $25.0-29.9$ & 14 & 7 & & \\
\hline & $\geq 30.0$ & 8 & 5 & & \\
\hline
\end{tabular}

Table 5. Association of food taboo practices with rates of weekly weight gain.

\begin{tabular}{|c|c|c|c|c|c|}
\hline \multirow[t]{3}{*}{ Food avoidance/taboo } & \multicolumn{3}{|c|}{ Weight gain rate of the subjects (kg/week) } & \multirow[t]{2}{*}{$\chi^{2}(\mathbf{d f})$} & \multirow[t]{2}{*}{ p value } \\
\hline & Inadequate & Adequate & Excessive & & \\
\hline & $\mathrm{n}(\%)$ & $\mathrm{n}(\%)$ & $\mathrm{n}(\%)$ & & \\
\hline Yes $(n=73)$ & $52(71.2)$ & $8(11.0)$ & $13(17.8)$ & \multirow[t]{2}{*}{$8.765(2)$} & \multirow[t]{2}{*}{$0.012 *$} \\
\hline No $(n=31)$ & $16(51.6)$ & $11(35.5)$ & $4(12.9)$ & & \\
\hline
\end{tabular}

of food avoidance is still very much in practice among the pregnant Malay women. The rate seems higher than the study conducted among Javanese in Indonesia $(37 \%)^{4}$ though the Malay and the Javanese have both similar origins and share many common cultures and traditions. For Javanese women, the main taboo during pregnancy was about observing their behavior rather than their food intake.

Though literature searched could not find a sufficient report on food taboo during pregnancy among the Malays, this study found pineapple as the most mentioned food avoidance because of its' abortive effect. The Malay believes that ingesting 'hot' substance such as pineapple; especially the unripe one can cause strong uterine contractions [20]. It is interesting to note that different fruits are thought to cause miscarriage in different culture. The Indians [11] believed that papaya is unsafe to be consumed by pregnant women. Whereas the Chinese [2] claim that banana is detrimental to pregnancy because it is thought to cause miscarriage if eaten in early pregnancy. While pineapple and papaya are categorized as 'hot' foods by the Malays [20] and the Indians [27] respectively; the Chinese, however, often categorize fruits and vegetables as 'cold' foods [16].

The concept of 'hot' and 'cold' foods is quite widespread but the underlying criteria of its classification are often not clear [27]. Although the Malays and the Indians believe that pregnancy is a hot condition [20,27], the Chinese, however, believe the pregnancy will cause a harmful disequilibrium of yin (cold) and yang (hot) in the body 
[38]. They believe the body will experience the cold condition in the first trimester and progress into a heart anomaly in the final trimester; hence pregnant women avoid 'cold' foods in the first trimester. They start eating cold foods only during the second trimester in order to counteract the hot condition that may come up in the final stage of pregnancy [29]. These observations reiterate reports on food taboo practices that were diverse and not absolute among different community $[18,27,30]$. Bolton reported that the food taboo can be local and personal, so much so that certain food can be transformed into non-taboo if it is found to have no ill-effect on the individual [18].

This study revealed that the main reason for not consuming the taboo foods was because of the health consequence to the mother themselves, such as abortion and excessive bleeding during labor and also to safeguard the birth outcomes of the babies, similar to what was witnessed in other cultures [2,3,5,7].

It is speculated that the relatively high prevalence of food taboos observed in this study is due to the high number of women in their first or second pregnancy. Most women who are pregnant with her first child are usually overly concerned with the pregnancy outcomes. They are easily influenced by the opinions and suggestions given by those who are close to them and/or by those who already had experienced pregnancies. This habit was clearly shown in this study whereby the majority of the subjects (63.5\%) got the information about food taboos from their family members. This study also found that the food taboo practices declined as the women experienced multiple pregnancies and it is evident that gravidity has a significant association with the practices $(\mathrm{p}<0.05)$. Almost a similar result was reported in a study among Nigerian women whereby it was revealed that primi-gravidity was associated with food taboos [3]. However, Nigerian study and our finding were contradicted with a study in Ethiopia, where it concluded that gravidity was not related to the food taboos practices [31].

Though gravidity did not influence food taboo practices among Ethiopian women, the study, however, found that educational level and income appeared to have an association on their food taboos. The Ethiopian study found women of low education level and lower income groups observed food taboos more as compared to women of better education and in the middle income group [31], which were contradicted by our findings. Our result also showed that no significant associations were found between age and pre-pregnancy BMI with food taboo practices.

Our finding shows a high number of pregnant women were not gaining the recommended weekly weight gain and there is a significant association between food taboos and the rate of weekly weight gain among the pregnant women $(\mathrm{p}<0.05)$. Apparently the percentages of not gaining the recommended weekly weight gain among those who practice food taboo was slightly higher $(71.2 \%)$ than those who were not adhering to the practice (51.6\%). This finding is almost similar to a study in Nigeria whereby they found that nearly three quarters of the pregnant women did not gain enough to meet the recommended weekly weight gain due to traditional beliefs of avoiding food during pregnancy rather than the more frequently cited reasons of poverty and non-availability of foods [32].

The high prevalence rate of the food taboos discovered in this study, underlines the need to further strengthen the effort to educate the mothers-to-be about nutrition knowledge during their antenatal check-up. Pregnant mothers visiting such health clinics should also be educated on dietary patters and healthy food habits. Emphasis should be given on the importance of consumption of fruits and vegetables in order to supply micronutrient and fibre to the body. Nutrition education should be conducted in all health centres to help pregnant women with healthier food choice to ensure the pregnant women understand the importance of good nutrition during pregnancy.

Convenience sampling method was used due to time constraint, though it might be biased as it may not represent the pregnant women population who came for the antenatal check-up. Secondary data which obtained from subjects' the medical records may not be accurate due to having variations in term of height and weight measurement technique of the measurers. The data on pre pregnancy weight were mostly being recalled by the subjects that might lead to recall bias. Most subjects found it very hard to complete the questionnaire as they required thinking and recalling especially when they were asked to give examples of certain food items they avoided. The questions were mostly open-ended type which largely depends on respondent cooperation, opinions and understanding.

\section{Conclusion}

The present study concludes that the prevalence of food taboos was alarmingly high with an inadequate weekly weight gain. The most common food the pregnant women avoided during pregnancy was pineapple due to its abortive effect or excessive bleeding during labor or the baby born with deformities. This study also shows that there is an association between food taboo practices and the rate of weekly weight gain.

\section{Acknowledgements}

Our deepest gratitude and appreciation to all the subjects who had participated in this study and special thanks to the Health Services of Malaysian Armed forces for their approval to conduct this study at its Maternal and Child Health clinic in Kuala Lumpur. We are also grateful to the International Medical University (IMU) Kuala Lumpur for providing a grant to conduct this work.

\section{References}

1. Meyer-Rochow VB (2009) Food taboos: their origins and purposes. $J$ Ethnobiol Ethnomed 5: 18. [Crossref]

2. Martin D (2001) Food restrictions in pregnancy among Hong Kong mothers, In: Wu DYH and Tan CB (Eds) Changing Chinese Foodways in Asia. The Chinese University Press: The Chinese University of Hong Kong: 97-122.

3. Oni OA, Tukur J (2012) Identifying pregnant women who would adhere to food taboos in a rural community: a community-based study. Afr J Reprod Health 16: 68-76. [Crossref]

4. Koeryaman MT (2012) Description of taboo behavior practice among pregnant women in West Java, Indonesia. Presented at the $23^{\text {rd }}$ International Nursing Research Congress, Brisbane Australia.

5. Patil R, Mittal A, Vedapriya DR, Iqbal Khan M, Raghavia M (2010) Taboos and misconceptions about food during pregnancy among rural population of Pondicherry Calicut Medical Journal 8: e4.

6. Sharifah Zahhura SA, Nilan P, Germov J (2012) Food restriction during pregnancy among indigenous Temiar women in Peninsula Malaysia. Mal J Nutr 18: 243-253.

7. Adamson DS (2015) The myths about food and pregnancy. BBC Magazine.

8. Wilson CS (1973) Food habits: A selected annotated bibliography. J Nutr Educ 5.

9. Trigo M, Roncada MJ, Stewien GT, Pereira IM (1989) [Food taboos in the northern region of Brazil]. Rev Saude Publica 23: 455-464. [Crossref]

10. Ferro-Luzzi EG (1980) Food avoidance of pregnant women in Tamil Nadu. In Robson JRK (Ed) Food, Ecology and Culture: Readings in the Anthropology of Dietary Practices. Gordon and Breach, Science Publishers, Inc: New York p101-108.

11. Puri S, Kapoor S (2006) Taboos and myths associated with women's health among 
rural and urban adolescent girls in Punjab. Indian Journal of Community Medicine 31: $168-170$.

12. Wilson CS (1980) Food taboos of childbirth: The Malay example. In: Robson JRK (Ed) Food, ecology and culture: Readings in Anthropology of Dietary Practices. Gordon and Breach, Science Publishers, Inc: New York p67-74.

13. Piperata BA (2008) Forty days and forty nights: a biocultural perspective on postpartum practices in the Amazon. Soc Sci Med 67: 1094-1103. [Crossref]

14. Sharifah Suraya SJ (2014) Beliefs and practices surrounding postpartum period among Malay women. Proceeding of the Social Sciences Research ICSSR 2014 (e-ISBN 978-967-11768-7-0). Kota Kinabalu, Sabah, Malaysia 409-417. Organized by http:// WorldConference.net

15. Sharifah Suraya SJ (2013) Penjagaan Kesihatan Wanita: Amalan Tradisonal dan Moden. Kuala Lumpur: Dewan Bahasa dan Pustaka.

16. Poh BK, Wong YP, Norimah AK (2005) Postpartum dietary intakes and food taboos among Chinese women attending maternal and child health clinics and maternity hospital, Kuala Lumpur. Mal J Nutr 11: 1-21.

17. Hishamshah M, Ramzan M, Rashid A, Mustaffa WW, Haroon R (2010) Belief and Practices of Traditional Post Partum Care Among a Rural Community in Penang Malaysia. The Internet Journal of Third World Medicine 9: 4210.

18. Bolton JM (1972) Food taboos among the Orang Asli in West Malaysia: a potential nutritional hazard. Am J Clin Nutr 25: 789-799. [Crossref]

19. Laderman C (1987) Destructive heat and cooling prayer: Malay humoralism in pregnancy, childbirth and the postpartum period. Soc Sci Med 25: 357-365. [Crossref]

20. Sudheer Pamidimarri DV, Reddy MP (2014) Phylogeography and molecular diversity analysis of Jatropha curcas L. and the dispersal route revealed by RAPD, AFLP and nrDNA-ITS analysis. Mol Biol Rep 41: 3225-3234. [Crossref]

21. Millis J (1958) Modifications in food selection observed by Malay women during pregnancy and after confinement. Med J Malaya 13: 139-144. [Crossref]
22. Islam MN, Ullah MO (2005) Knowledge and Attitude of Urban Pregnant Women of Bangladesh Toward Nutrition, Health Care Practice and Delivery Place. Journal of Medical Sciences 5: 116-119.

23. Viswanathan M, Siega-Riz AM, Moos MK, Deierlein A, Mumford S, et al. (2008) Outcomes of maternal weight gain. Evid Rep Technol Assess 1-223. [Crossref]

24. Siega-Riz AM, Viswanathan M, Moos MK, Deierlein A, Mumford S, et al. (2009) A systematic review of outcomes of maternal weight gains, according to the Institute of Medicine recommendations: birth weight, fetal growth, and postpartum weight retention. Am J Obstet Gynecol 201: 339. e1-14.

25. World Health Organization (2000) The Asia-Pacific Perspective: redefining Obesity and its treatment 2000. World Health Organization, Geneva, Switzerland.

26. Institute of Medicine (2009) Weight gain during Pregnancy: Reexamining the guidelines. Report brief. May 2009.

27. Moni N (1994) Belief and practices about food during pregnancy. Economic and Political Weekly pp 2427-2438.

28. Tung WC (2010) Doing the month and Asian cultures: Implications for health care Home Health Care Manag Prac 22: 369-371.

29. Notes on Food in Nutrition and Health in Traditional China (1991) In Food in China A cultural and Historical Inquiry; Simoons FJ, ed; CRC Press Boston MA USA pp 469-515.

30. Gao H, Stiller CK, Scherbaum V, Biesalski HK, Wang Q, et al. (2013) Dietary intake and food habits of pregnant women residing in urban and rural areas of Deyang City, Sichuan Province, China. Nutrients 5: 2933-2954.

31. Gemebo TD (1996) Food aversion, craving and taboo of pregnant women in Hadiya zone, Ethiopia: prevalence and their significance in maternal nutrition. Digital Repository, Universiti of Nairobi.

32. Ojofeitimi EO, Tanimowo CM (1980) Nutritional beliefs among pregnant Nigerian Women. Int J Gynaecol Obstet 18: 66-69.

Copyright: @2016 Mohamad M. This is an open-access article distributed under the terms of the Creative Commons Attribution License, which permits unrestricted use, distribution, and reproduction in any medium, provided the original author and source are credited. 